\title{
Supporting parents of children with type I diabetes mellitus: a literature review
}

This article was published in the following Dove Press journal:

Patient Intelligence

20 October 2015

Number of times this article has been viewed

\section{Leehu Zysberg'}

Tali Lang ${ }^{2}$

'Graduate School, Gordon College of Education, ${ }^{2}$ Department of Nursing,

University of Haifa, Haifa, Israel
Correspondence: Leehu Zysberg Gordon College of Education

73 Tchernichovski Street, Haifa 3570503, Israel

Tel +972 58487777 I

Email leehuzysberg@yahoo.com
Abstract: This review provides the reader with an integrative view of the literature on the challenges families of patients with type 1 diabetes mellitus face, and the interventions proposed in research and practice to facilitate their coping and efficacy in supporting patient care. We present background information regarding the condition and the general challenges it poses, and then focus on younger patients and their families, while reviewing the literature and emerging patterns describing pitfalls and proposed interventions. We present directions for future thought and further research based on what we find (and fail to find) in the literature.

Keywords: challenges, interventions, patient care, blood sugar, emotional, psychological

\section{Introduction}

Type 1 diabetes mellitus (T1DM) is a condition affecting younger patients, challenging them with life-threatening outcomes. The condition requires that patients adopt a restrictive lifestyle and diet, and monitor their blood sugar levels frequently. The young patients, naturally, must rely on their parents and families for instruction, support, and daily help with coping with such a complex set of demands. Moreover, beyond the challenges of daily care and monitoring, living with the constant threat of health deterioration and future complications, the young patients face emotional and psychological difficulties that reflect on their own coping as well as their social circle and family.

The condition may therefore be considered "a family condition" challenging the patients' entire social and familial circle in numerous ways. While the literature is replete with medical aspects of diagnosis and care of T1DM, less has been written about the patients' family and social circles. The purpose of this review then is to provide a current overview of the main trends and direction emerging from the literature regarding the challenges the patients' families and social milieu face, as well as highlight interventions studied in this context. While this is not intended as an exhaustive literature review, it does provide a representative coverage of the literature, issues addressed and interventions proposed, based on systematic searches using the MEDLINE Google scholar and PsycINFO search engines using common keywords appearing in the literature, focusing mainly on manuscripts published after 2000 . We included older seminal literature where we deemed it necessary.

We first present background information regarding T1DM and the challenges it poses to individuals and their families. We later explore areas the literature identifies as major issues and the factors associated with them. We then review interventions and offer a few directions for future thought and research. 


\section{Care in context: diabetes incidence and prevalence}

Diabetes is a group of metabolic diseases characterized by hyperglycemia resulting from deficits in insulin secretion, insulin resistance, or both. According to the World Health Organization, in the 21 st century, diabetes has become a major challenge for health care systems worldwide. It is the seventh leading cause of death in developed countries. ${ }^{1}$

In the US, 29.1 million people (9.3\%), 208,000 of them under the age of 20 years, have been diagnosed with diabetes (type 1 or type 2). The prevalence of the condition among all age groups has been increasing in recent decades. ${ }^{2}$

\section{Type I diabetes mellitus}

T1DM, one of the most common chronic diseases of childhood, can be diagnosed at any age; peaks in onset occur between 5 years and 7 years of age and at or near puberty. T1DM accounts for $\sim 10 \%$ of all diabetes cases, and the incidence rate of childhood T1DM has risen worldwide by $\sim 2.8 \%-4.0 \%$ each year in all age groups in the last several decades. ${ }^{3}$ The greatest increase in new-onset T1DM is seen in children $<5$ years old in the EU. ${ }^{4}$ T1DM is most common in Europe $(129,000)$ and North America $(108,700)$ and far less common in People's Republic of China, India, and Africa. Such geographical variations have also been found in other autoimmune diseases such as multiple sclerosis and inflammatory bowel disease. ${ }^{5-7}$

The underlying mechanism of the disease has been debated widely. Genetic predisposition, environmental influences, vitamin D processing, and viruses have been identified as the most likely agents in pathogenesis of T1DM.,5 To this date, however, there is no robust evidence identifying its main causes.

The rise in the prevalence and earlier onset of T1DM leads to longer chronic conditions and a heavier burden on formal support systems and informal caregivers, particularly for patients in early childhood. ${ }^{2}$

\section{The main challenges of TIDM treatment}

Management of T1DM is complicated and requires understanding the disease while coping with often-challenging lifestyle changes (eg, dietary restrictions) as well as challenging, daily maintenance treatments (eg, insulin injections). Adequate management requires regular blood glucose monitoring and insulin baseline-bolus treatment. ${ }^{8}$ Several methods exist for insulin delivery, for example, multiple daily injections (MDIs) and continuous subcutaneous insulin infusion (CSII) by insulin pump/pod. According to the CSII method, the patient must carry on his or her body a device infusing insulin continuously by subcutaneous connection. In addition, insulin management through a pump requires carbohydrate count before each meal and manual infusion of insulin according to glucose rate through the pump/pod. ${ }^{9,10}$ Most of the care involved in T1DM management is selfcare (especially with preteens and teenagers) that requires self-discipline and endurance in the face of continuous frustration, discomfort, and pain. An integral part of intensive self-management of diabetes is frequent glucose monitoring by finger-stick measurements. The challenges of adequate glucose monitoring are the associated pain, financial cost, behavioral and technical skills, motivation, and exposure to repeated intrusive procedures. These challenges directly affect adherence and pose barriers to tight glycemic control. ${ }^{11}$ A recently developed continuous glucose monitoring device records blood glucose levels throughout the day and night by subcutaneous connection and has alarms for hypo- and hyperglycemia. The device is designed to achieve better glycemic control and to decrease hypoglycemic episodes.

Despite a number of improvements in pharmacotechnology in the last decade, including the use of analog insulin and a great variety of delivery devices, the burden on the patients and the people around them is significant, and there has been no meaningful improvement in achieving metabolic/glycemic control in children and adolescents. ${ }^{12,13}$

\section{Introduction to the relevance of family involvement: factors associated with glycemic balance}

Families of children with T1DM are required to commit to and support lifestyle changes that adhere to published recommendations for glycemic control. The challenge is made even more daunting as families realize that although these restrictive guidelines decrease risks of long-term complications, they do not result in immediate, noticeable changes for better or worse. ${ }^{14}$

Family routines and interactions can become stressful when parents and a child spend time on multiple glucose tests and insulin injections that are aversive to both child and parents and that might serve as constant reminders to everyone involved of the condition. ${ }^{15}$ Today, youth with T1DM are mostly prescribed intensive insulin regimens, that is, undergoing MDI or managing an insulin pump. The physical and mental challenges of insulin-intensive treatment only partially explain the high variability in the disease's metabolic control in patients with diabetes in all age groups. ${ }^{16-18}$ Many researchers have attempted to identify the factors associated 
with more effective management of T1DM, including age of child, socioeconomic status (SES), ethnic group, familial stress, and familial interaction. ${ }^{18,19}$

\section{Age of patient}

Physical developmental processes and puberty change one's lifestyle and habits. Such disruptions are associated with reduced glycemic control. A retrospective study that collected data from children and adolescents from 30 medical centers in 16 European countries found that preschool children showed a significantly lower $\mathrm{HbA}_{1 \mathrm{c}}$ than adolescents, with a mean $\mathrm{HbA}_{1 \mathrm{c}}$ value of $7.6 \% \pm 1.0 \%$, compared with $8.3 \% \pm 1.4 \%(P<0.0001)$ in the adolescent group. ${ }^{20}$ Among possible explanations for the gap, studies include factors such as physical and sexual development, behavioral changes that affect adherence to diabetes treatment, and self-management ability. ${ }^{17}$ Another factor that seems to interact with age is the level and style of parental involvement as the children age: studies have shown that parental involvement and its effectiveness in maintaining glycemic control vary over time as the young patients age. ${ }^{21}$ Another interesting aspect that is given much less attention in the existing literature is later age transitions: While children and adolescents with T1DM have been the subject of substantial investigation, young adults and their interactions with their peers, families, and other social circles in light of their condition received much less attention. A recent position paper ${ }^{12}$ suggests that the transition from childhood and adolescence - often characterized by higher levels of parental supervision - into adulthood (often associated with moving out of home, increased independence) is a sensitive point where transition of care and support is inadequately understood and practiced. Even less is known about the changing role of family support and availability during this transition. ${ }^{22}$ Existing research only begins to unravel the changing family interactions around these transitions.

\section{SES and ethnic background}

A literature review of English-language studies that were published between January 1985 and May 2009 suggests that children of ethnic minorities in the US bear a greater health burden and experience poorer outcomes than white chronically ill children. ${ }^{23}$ Additional research strengthens this hypothesis and shows that African American children in particular suffer from poorer metabolic control due to lower family income that precludes the purchase of proper health insurance and care. ${ }^{24}$ Despite the strong evidence of negative correlations between SES and metabolic balance,
Kichler et $\mathrm{al}^{25}$ surprisingly argue in their research that in a study of Hispanic youth with T1DM, those having a more recent generational status (ie, their parents had immigrated more recently) in the US exhibited better adherence. The authors hypothesized that those who are less acculturated may have greater respect for medical staff, which may be associated with better adherence. Another interpretation may be related to the role of family support: in traditional families, parents may exert more supervision and gain compliance more effectively. Evidence also suggests that SES and ethnicity may affect diabetic control outcomes separately and differentially, despite the general association between both factors. $^{26}$

\section{What to worry about: areas of concern and interventions with TIDM patients and their families}

The literature reviewed above emphasizes repeatedly the importance of aspects of a patient's environment, whether socioeconomic, cultural, social, or emotional. ${ }^{27,28}$ Although age plays an important role in how influential these factors are, their relevance remains altogether consistent from early childhood to adulthood and thus is worth a second look.

The literature is replete with evidence of the emotional and psychosocial toll of diabetes on patients, but the families of T1DM patients, especially young patients, have traditionally received far less attention. In the last 20 years or so, evidence has mounted of the predicament facing the family of the younger person diagnosed with T1DM. ${ }^{25}$ The predicament is made even more challenging and important to address as we realize not only that the diagnosis of T1DM throws the whole family into psychosocial havoc but also that this havoc in turn directly and indirectly influences the effectiveness of monitoring and care of the condition. ${ }^{25,29}$ In the following paragraphs, we delineate this predicament to better understand what family-focused interventions are targeting.

\section{TIDM in young patients and parental distress}

The experience of being diagnosed with T1DM is already acknowledged in the literature as a traumatic and challenging life event. Less acknowledged is the experience of the family of the young patients, realizing the harsh consequences of the diagnosis for their children's quality of life, life expectancy, and daily routines. Slowly, they also realize that this new reality has direct implications for the whole family. And indeed, studies have identified deep emotional distress in parents of T1DM patients. ${ }^{30}$ Managing young people's 
diabetic conditions requires changes in routines, in attention, and in diet, and in lifestyle. The daily routine may become a source of family debates and conflicts: young patients may not always understand and meet parental expectations to adhere to testing and care protocols. ${ }^{31-33}$ In addition, there is the challenge of living with a constant threat of deterioration, repeated hospitalizations, and the danger of gradual functional decline which generates additional stress and burden, beyond daily care. ${ }^{32}$

Emphasis on caring for parents and families of T1DM has begun to take center stage in the last 20-25 years. But this emphasis targets not only the well-being of the family cell but also the direct effective management of the patient's condition.

\section{Family interaction: a key to balancing young TIDM patients?}

The challenge of managing childhood chronic illness often becomes a central theme in families with affected children and may create much stress for the whole family unit. Psychosocial factors have a significant influence on the dayto-day management of T1DM and have been associated with metabolic control. ${ }^{29}$ Parents spoke of the disappointment and even shame they feel when diabetes management is not going well or when the child or adolescent becomes increasingly resistant to their management. ${ }^{16}$ Interaction between parents and between parents and their children is generally agreed to be a major factor in glycemic management; however, others suggest that such interactions may not be consistent in how, and how much, they shape health outcomes. Pendley et $\mathrm{al}^{34}$ argued that although peer interactions may be associated with physiological markers of glycemic control during adolescence, family interactions and relationships may not have a direct effect on the same outcome measures.

The debate notwithstanding, there is a generally accepted view of the family unit and the interactions among its members as a major factor in physiological, psychosocial, and functional outcomes of long-term care of T1DM.

However, the role of family interactions in this context has more complexity than first meets the eye. The role of family interaction in children's T1DM was highlighted with the publishing of a seminal work by Minuchin et al (1988, cited in the study by Coyne and Anderson ${ }^{35}$ ) who coined the term "the psychosomatic family". The term describes interaction and communication patterns in families that produce and promote somatization in children and that may cause and trigger illness, including T1DM. Although fiercely debated, the notion has highlighted the immense power of family ties and interaction dynamics in health and health management in the current context. Since the introduction of the "psychosomatic family" idea, numerous studies - some correlational or cross-sectional and others using experimental controlled trials - have demonstrated how quality of family interaction, communication, and conflict management affect physical outcomes in T1DM patients. ${ }^{29,33,36}$ In reviewing the literature on family interaction and diabetic management, we found the following to repeatedly emerge as leading factors predicting diabetic outcomes.

\section{Social support}

This is perhaps the strongest, most consistently supported factor in the empirical literature. The availability of supportemotional, informational, and physical - plays a major role in accounting for effective care of T1DM, as well as stress reduction and enhanced well-being. ${ }^{36-38}$

\section{Conflict and conflict management}

Parents and children do not always see eye to eye. Such conflicts might be exacerbated by stress emanating from the complexity and frustrations inherent in T1DM management, especially with young and adolescent children. ${ }^{34,39}$ Studies have found associations between more frequent, less effectively managed conflict and adherence issues around treatment of the condition.

\section{Technical and practical knowledge and know-how}

Monitoring and caring for a diabetic patient takes skills, including among them administering frequent blood tests, balancing nutrition and monitoring, and managing physical activity. Training patients and their parents (and some include siblings and peers - discussed in "Family interactions around patients with T1DM - a complex picture" section) to become proficient at caring for themselves not only is instrumental but also provides a sense of control over the condition. ${ }^{40}$

Before reviewing the literature on how these content areas are implemented in various intervention programs and studies, we take another look at the challenges such interventions target.

\section{The challenges families face}

A number of specific challenges in the care of T1DM patients and their families have been identified by researchers and practitioners. These include 1) facilitating adherence to testing and diabetic management behaviors, 2) diagnosing and caring for related psychosocial comorbidities of T1DM (eg, depression), and 3) supporting and facilitating adaptive 
family interaction, communication, and dynamics (often disturbed by the illness and the care protocols).

\section{Facilitating adherence to testing and diabetic management behaviors}

The most immediate goal of interventions with T1DM patients and their families is increasing adherence to monitoring and care. These interventions fall into two categories: 1) educational-informational interventions and 2) behavioral interventions aimed at supporting health-promoting behaviors.

Murphy et $\mathrm{al}^{41}$ reviewed the literature covering 24 different educational interventions for T1DM patients and their families. Interventions are aimed at two specific populations - the newly diagnosed and those in the years after diagnosis. For the newly diagnosed, most interventions focus on informing and preventing cases of extreme hyper- or hypoglycemia. Interventions in subsequent years take multiple forms and obviously lack an empirically supported golden standard for content, technique, and methodology. ${ }^{30,42}$ These vary from self-study materials and informational sessions to technical training (to develop proficiency with diabetic care procedures), motivational (individual or family) interventions, behavioral interventions to facilitate coping with stress, and support groups for patients and families. ${ }^{17,30}$ The range of interventions is matched by the range of diverse methodologies used to test them in the literature. Reviews spreading across the last 15 years highlight the lack of randomized controlled trial studies to test interventions and the overuse of cross-sectional and correlational studies. ${ }^{42,43}$ Not surprisingly, given the inconsistency of content, methodology, and research design, literature reviews report a moderate size effect for both physiological indicators of glycemic control and psychosocial outcomes. ${ }^{42}$ Moreover, the literature is inconsistent regarding the potential associations between behavioral outcomes (motivation, well-being, family outcomes, etc) and measures of glycemic control and balance. This inconsistency, however, might be due to inconsistency in methods and measures. A randomized controlled trial study of behavioral family systems therapy in young patients with poor glycemic control indices in the $\mathrm{US}^{44,45}$ yielded more consistent results for both intervention outcomes and the associations between behavioral and motivational measures and physiological indicators of glycemic control and balance. To sum up, for this domain of patient and family interventions, the literature reflects inconsistency and lack of standardization. Interventions are loosely anchored in theory or empirical evidence and vary dramatically between settings. Worse, studies examining or reporting these interventions vary as much in methodology, design, and selection of outcomes. As a result, recent reviews of the research in this venue point to a moderateto-low effect size of such interventions. However, select studies reporting methodologically sound trials show significant effects and point to directions for future research and practice.

\section{Diagnosis and care of related psychosocial comorbidities of TIDM}

The medical literature on young patients with T1DM often disregards a sad reality: the disease and its treatment are often associated with other challenges, or comorbidities. The need to cope with a challenging health- and sometimes life-threatening condition that requires painful and restrictive monitoring and care, at a young age, often takes its toll on patients and their families. Here, we dwell on a few of these comorbidities.

Depression is the most common and most dangerous comorbidity, as it is associated with a marked decrease in self- and family-care effectiveness, repeat hospitalizations, and poorer $\mathrm{HbA}_{1 \mathrm{c}}$ levels. ${ }^{46}$ Interventions include, first and foremost, early diagnosis of the condition, building and maintaining support systems (usually from within the family but also through support groups, peer support, and other resources), and clinical interventions for patients and family. Congruence in patients' and family perceptions is also associated with positive outcomes; thus, interventions based on communication and conflict management within the patient's family are an objective of some interventions. ${ }^{42,44}$

Additional comorbidities associated with T1DM across the life span have to do with decreased cognitive function. ${ }^{47}$ Studies report changes in brain structure and blood circuitry and flow that have been associated with decreased cognitive abilities, memory capacity, and performance on ability tests from early childhood. ${ }^{48}$ Authors suggest the existence of crucial periods in which brain development and brain plasticity are most marked, where interventions are aimed at glycemic balance and improved microcirculation. ${ }^{49}$ These may include medication, physical activity, and support in educational and training settings.

Eating disorders (EDs) are also more common in young patients with T1DM. ${ }^{50}$ The literature proposes that the prevalence of all diagnosed EDs among T1DM patients is eight to ten times higher than in the general population, and they present immediate heightened risk, since they interfere 
with diabetic control as well as the risks associated with the condition in the general population. ${ }^{51}$ The most common form of disturbed eating patterns includes skipping insulin doses (to reduce weight gain due to higher levels of insulin), binge eating, and excessive exercise. Only a few anorexia or bulimia cases are reported in the literature. Intervention programs abound, but few target T1DM patients specifically. ${ }^{52}$ A fairly recent exploration of the factors contributing to the risk of $\mathrm{EDs}^{51}$ proposes early detection of risk factors (among them sex, age, body dissatisfaction, disease onset, and others) and preventive intervention if possible. Family support, supervision, and emotional support are among the main therapeutic elements mentioned in the literature. However, their efficiency in this specific population is still under investigation. ${ }^{53}$

Substance abuse is yet another comorbid pattern with an increased incidence in adolescents and young adults with T1DM. ${ }^{54}$ The etiology of the phenomenon in T1DM is often attributed to a combination of factors, including developmental socio-emotional challenges associated with the transition into and from adolescence, pain avoidance, and maladaptive attempts to cope with disease-related stress. ${ }^{54,55}$ Proposed interventions target these factors, addressing effective stress management, family interactions, and support, drawing of course on years of experience gathered with substance-abuse interventions in the general population. ${ }^{54}$ These interventions become more complex and challenging when facing the factors associated with T1DM that push young patients into substance abuse to begin with.

To sum, it seems that - as with any complex health condition - comorbidities pose an added burden and challenge for patients and families alike. These may be a by-product of the condition's etiology or "opportunist" conditions that manifest when defenses and coping resources are taxed. Most interventions in this area are modeled after existing "generic" preventive measures - aimed at early detection, or if possible, at identifying individuals and families at risk. Providing support early on is the easiest and most effective intervention in the long run. When early detection is not possible, interventions aim at the following: to support and provide more effective coping techniques; to provide a more supportive, less conflicted (and stress-inducing) environment; and to empower families, peers, and other social circles available to patients to provide better support as well as supervision, depending on patient age and status. This field of research and practice is especially crucial because it addresses burdens beyond the disease's immediate challenges. These burdens might take an additional toll on individuals and families and therefore call for additional research, in directions and potential pathways we discuss later in this review.

\section{Support and facilitation of adaptive family interaction, communication, and dynamics}

Effectively managing a young patient's T1DM is taxing for both the patient and his or her caregivers. The need to manage numerous aspects of lifestyle (eg, physical activity, dietary restrictions, numerous needle pricks for testing) is often a source of conflict among family members and strains the delicate fabric of family interactions. ${ }^{56}$ Sources of conflict vary from interactions around adherence to testing and care routines to fear of hypo- or hyperglycemic events to anxiety around activities and which should be restricted (and which not). Whatever drives conflict in such settings, the literature seems consistent in suggesting that conflict and instability of family interactions are associated with instability in care and monitoring of the condition. ${ }^{39}$ Research has focused on a few angles worth a quick review here.

\section{Parenting style and diabetic outcomes}

This line of research addresses the conceptual framework of "parenting style". ${ }^{57}$ The term refers to typical patterns of communication and exertion of authority on behalf of parents in their interactions with their children. Existing research associates various patterns (or parenting styles) with aspects of adaptation, performance in various settings, and psychological well-being in adolescents. The literature differentiates between four typical parenting patterns: authoritarian, in which communication is unidirectional and enforcement is fierce ("my way or the highway"); authoritative, in which communication is bidirectional: the child is heard and is involved in decision making but the parents make the final call; permissive, in which parents may advise their children and inform them but will leave the final decisions to them; and neglecting, in which parents show little to no interest in their child's behavior and minimize their involvement. ${ }^{58}$ Recent findings in the field of T1DM management show interesting associations between parenting styles and the effectiveness of various aspects of diabetic management in young patients. The most common results suggest that the involved and demanding (authoritative) parenting styles are most effective. ${ }^{57}$

Based on such insights, most interventions with families of young T1DM patients focus on parenting style: both in identifying the existing style in a given family and on modifying and changing it if needed. Such interventions might in 
the short term increase the experience of stress in the family, since such change never comes easy. However, long-term changes may help reduce conflict and improve the experience of family interactions around the care of the condition. ${ }^{59}$

\section{Family interactions around patients with TIDM - a complex picture}

How the literature conceptualizes the family dynamics around the care of a T1DM patient has evolved dramatically over the years from a unidimensional view of family interaction (eg, positive-negative) to a complex network of associations and interactions, and from parental interaction to a broader view of the larger family context. ${ }^{59}$ The age of the T1DM patients and the developmental implications of shifting relationship patterns were also recently included in studies that explored the relative importance of parents, siblings, and peers across the shifts from early childhood through adolescence to early adulthood. ${ }^{10,15,19}$ Recent shifts of interest include, among others, from a focus on mothers' interactions with their children to exploring fathers' role in shaping family interactions around T1DM management, greater emphasis on the role of the peer group as a source for support (or lack of it) especially during adolescence, and the role of other family members in the patient's natural settings. ${ }^{37,40,60}$

An additional emphasis is raising concern over the toll of caring for a T1DM patient on other family members. Recent studies show signs of burnout in parents of chronically ill children. ${ }^{61}$ Such burnout, of course, may first compromise the function and well-being of the parents themselves and thus the well-being of the whole family. Surprisingly, the diabetes research community is only recently opening up to this idea. ${ }^{56}$ An additional source of worry that is only indirectly mentioned in recent literature is the psychological toll on the siblings of the young T1DM patient. First is the worry of developing the same condition, since heredity and family factors play a significant role in its onset. ${ }^{62}$ Then, there are the consequences of years of family interactions revolving around the treatment of the T1DM patient: siblings may resent the attention the sick sibling receives, may feel guilty for not being sick like their sibling, and may feel conflicted around their role as potential caregivers. ${ }^{63}$ While the literature on chronic illness in general is replete with references to this issue, the diabetes care literature seems to lack in this respect, and more research is needed to better understand the predicament of siblings of T1DM patients, especially through the earlier years of life.

Interventions targeting the above aspects focus on a few intermediate goals: effective stress management, self-management and maintaining "selfhood" when caring for others (usually in the context of reducing burnout), and effective communication/conflict management. ${ }^{64,65}$ The literature is, however, somewhat inconsistent about the outcomes of such interventions. Although the overwhelming majority of the studies support improvement in family interactions and dynamics, its association with diabetes-management outcomes is somewhat more complex, and future research might elaborate more on the linkages between support, family dynamic, and patient outcomes.

\section{Interventions with families of TIDM patients: what's out there?}

The directions and trends described here provide insight into the foci of attention and methods used in designing and providing interventions to support families of T1DM patients, with emphasis on early age through early adulthood. But what is being done? What interventions are described in the literature? And how are they delivered?

Table 1 is a representative, although not exhaustive, list of studies describing such interventions. Items and interventions were selected for this summarizing table based on the following criteria: 1) intervention was at under preliminary empirical test of its outcomes and effectiveness, 2) intervention touched either patients and their families (or peers) or families only, and 3) interventions offered novelty or added value (replications and implementation reports were excluded).

The sample of studies summarized in Table 1 represents a broad range of approaches, frameworks, and even technologies, but all share the same core targets: social support, communication and conflict management, and practical/ technical knowledge. Coping and coping skills training is also emphasized in many of the programs, harnessing models borrowed from the field of psychology. Another aspect that emerges from some of the studies is the new reality of multiculturalism. As cultures set frames of reference to assess and evaluate reality, as well as language and communication patterns, more and more health authorities invest in communicating health messages and training to diverse target populations. In recent years, the use of technology (especially portable information and communication technology) allows professionals and families to better approach and remain accessible to the "flat screen" generation. Such technologies may also prove promising in addressing accessibility challenges (for remote target populations or disadvantaged populations who may not have access to good health services). 
Table I A sample of interventions from the empirical literature on family support for patients with TIDM

\begin{tabular}{|c|c|c|}
\hline Comments & Intervention type/outline & Source \\
\hline $\begin{array}{l}\text { Relationship quality and effective communication, } \\
\text { problem solving associated with better adherence } \\
\text { to care }\end{array}$ & $\begin{array}{l}\text { Mothers and their TIDM daughters discussed emotional issues, } \\
\text { conflicts, and concerns based on structured tools }\end{array}$ & $\begin{array}{l}\text { Bobrow } \\
\text { et al }{ }^{68}\end{array}$ \\
\hline $\begin{array}{l}\text { MF group interventions with simulations were found } \\
\text { to be most effective, even at } 6 \text {-month follow-up }\end{array}$ & $\begin{array}{l}\text { MF group format for intervention with families of TIDM young } \\
\text { patients. Discussions and simulations were included in three } \\
\text { different conditions }\end{array}$ & Satin et $a^{69}$ \\
\hline $\begin{array}{l}\text { Showed an association between intervention } \\
\text { and better compliance with treatment regimen } \\
\text { and diabetes outcomes }\end{array}$ & $\begin{array}{l}\text { A brief family-based behavioral therapy program for diabetic } \\
\text { adolescents/training in parent-teen communication skills, } \\
\text { problem solving, and specific goal-setting with behavioral contracts } \\
\text { was used to improve selected aspects of regimen adherence }\end{array}$ & $\begin{array}{l}\text { Delamater } \\
\text { et } \mathrm{al}^{70}\end{array}$ \\
\hline $\begin{array}{l}\text { Study showed lower chance of deterioration in } \\
\text { diabetes-management indices in the intervention group }\end{array}$ & $\begin{array}{l}\text { Low-intensity intervention program aimed at improving teamwork } \\
\text { and collaboration in the family around care routines of patients }\end{array}$ & $\begin{array}{l}\text { Anderson } \\
\text { et } \mathrm{al}^{64}\end{array}$ \\
\hline $\begin{array}{l}\text { Results showed improvement in family relations } \\
\text { indices but not physical indices of diabetes control }\end{array}$ & $\begin{array}{l}\text { Behavioral family systems therapy, focusing on communication styles. } \\
\text { Teamwork within the family }\end{array}$ & $\begin{array}{l}\text { Wysocki } \\
\text { et al }{ }^{59}\end{array}$ \\
\hline $\begin{array}{l}\text { Preliminary evidence suggests change in attitude } \\
\text { and involvement in support of care from peers }\end{array}$ & $\begin{array}{l}\text { Group intervention program aimed at TIDM teens and their best } \\
\text { friends (peers), increasing knowledge and shaping attitudes toward } \\
\text { the condition and its care }\end{array}$ & Greco et al \\
\hline $\begin{array}{l}\text { Results supported lower rates of deterioration } \\
\text { in the intervention group across time }\end{array}$ & $\begin{array}{l}\text { Ambulatory intervention for young patients and their family to reduce } \\
\text { conflict around diabetes management, and in-family teamwork }\end{array}$ & Laffel et al ${ }^{65}$ \\
\hline $\begin{array}{l}\text { Therapy group has lower rates of glycemic events } \\
\text { and hospitalizations }\end{array}$ & $\begin{array}{l}\text { MST, an intensive home-based psychotherapy, aimed to reduce } \\
\text { hospital admissions for children with diabetes }\end{array}$ & Ellis et $\mathrm{al}^{72}$ \\
\hline $\begin{array}{l}\text { Pre-post measures show increased knowledge and } \\
\text { involvement in diabetes management in families }\end{array}$ & $\begin{array}{l}\text { Multicultural and multilingual (Spanish) educational support for families } \\
\text { of adolescents with diabetes living on the Mexico border in the US }\end{array}$ & $\begin{array}{l}\text { Teufel- } \\
\text { Shone et al }\end{array}$ \\
\hline Found effective mainly for preadolescents & $\begin{array}{l}\text { Behavioral interventions where parents learned to shape } \\
\text { health-supporting behavior of their children }\end{array}$ & $\mathrm{Carr}^{74}$ \\
\hline Reduced stress, slightly better compliance with care & $\begin{array}{l}\text { Psycho-educational programs for adolescents with newly } \\
\text { discovered TIDM, with their families }\end{array}$ & $\mathrm{Carr}^{74}$ \\
\hline Equivocal outcomes & $\begin{array}{l}\text { Social-support intervention with parents of children }<13 \text { years old } \\
\text { newly diagnosed with TIDM, via home visits and telephone }\end{array}$ & $\begin{array}{l}\text { Sullivan- } \\
\text { Bolyai et al }{ }^{7}\end{array}$ \\
\hline $\begin{array}{l}\text { Evidence suggests increase in efficacy measures } \\
\text { in a pre-post measure }\end{array}$ & $\begin{array}{l}\text { An online platform to increase knowledge, self-efficacy of parents } \\
\text { caring for TIDM children }\end{array}$ & $\begin{array}{l}\text { Merkel and } \\
\text { Wright }^{60}\end{array}$ \\
\hline Pilot results are limited but promising & $\begin{array}{l}\text { Motivational interviewing combined with cognitive-behavioral therapy } \\
\text { to increase motivations to engage in effective diabetes management }\end{array}$ & $\begin{array}{l}\text { Stanger } \\
\text { et } \mathrm{al}^{76}\end{array}$ \\
\hline $\begin{array}{l}\text { Only a preliminary feasibility study supports } \\
\text { the potential of the intervention }\end{array}$ & $\begin{array}{l}\text { SMART: a text-messaging-based intervention program. } \\
\text { Teenagers texted their } \mathrm{HbA}_{\mathrm{Ic}} \text {, blood sugar level, and nutrition } \\
\text { over the 6-week intervention program }\end{array}$ & $\begin{array}{l}\text { Herbert } \\
\text { et } \mathrm{al}^{77}\end{array}$ \\
\hline $\begin{array}{l}\text { Both the coping skills and the educational groups } \\
\text { reported improvement, but no group differences } \\
\text { were found }\end{array}$ & $\begin{array}{l}\text { Coping skills training compared with educational interventions } \\
\text { with parents of Children with TIDM. Intervention aims at } \\
\text { increasing self-efficacy and hence reduce care-related stress }\end{array}$ & Grey et $\mathrm{al}^{78}$ \\
\hline
\end{tabular}

Abbreviations: TIDM, type I diabetes mellitus; MF, multifamily; MST, multisystemic therapy; SMART, Self-Management and Research Technology.

\section{Some insights and thinking ahead}

As medicine, psychiatry, and numerous other therapeutic professions incorporate context more and more into models and practice, the treatment of T1DM in context is first and foremost that of the family. The family sets the stage on which diabetes is triggered, and it may either buffer the challenges the condition presents or exacerbate them. The literature has suggested a few axes along which families vary that are associated with effective management of diabetes in children and adolescents. These are support, conflict management, and practical guidance and help. What seems to be common to these aspects is the family's ability to handle emotionally laden situations effectively while controlling health-related behaviors on behalf of children. Most interventions target (directly and indirectly) these aspects of the family dynamics around the illness and its management: first is education and knowledge, followed by problem solving and other coping skills, alongside attention to family dynamics and interactions - modeled to provide much needed support first and foremost to the patients but also to family members. While many of the interventions and much of the literature adopt classic behavioral theories and models, current authors bring us to the realization that these models might not be as universal as we thought: culture is a relatively recent major player in how we design and implement such interventions, or assess their outcomes. Another recent trend has more to 
do with means than content in the proposed interventions: the use of advanced and mobile technology to provide support, monitoring, and communication channels to patients and their families.

Having identified these common threads in the literature, one cannot but realize the crucial roles of emotion and emotion regulation, as well as interpersonal interaction in all of the abovementioned directions. A recently presented concept may hold promise for our understanding of this common denominator: emotional intelligence (EI). EI refers to individuals' ability to identify, process, and regulate emotions effectively in themselves and others. ${ }^{66}$ The key role EI may play in health maintenance and health care is only beginning to be unraveled. A recent study with T1DM patients and their parents suggests that parents' EI may play a pivotal role in their children's diabetes management. ${ }^{32}$ Another study proposes that EI levels in young adult T1DM patients are associated with their $\mathrm{HbA}_{1 \mathrm{c}}$ levels and blood sugar levels. ${ }^{67}$ In light of the literature reviewed here, we can draw a path linking individual levels of EI in family members - facilitating coping and adapting effectively to the challenges of diabetes care - resulting in better physical indices of diabetes management.

What's left unknown? Where should we look in designing future research? Although the associations between various aspects of family function and dynamics and diabetes outcomes are quite well delineated at this stage, the underlying mechanisms are just beginning to be explored (EI being an example of one such possible mechanism). Future research might further explore the underpinnings of and underlying processes governing the association patterns revealed thus far. Individual abilities, personality tendencies, and family dynamics and communication styles are a few directions explored in the past that may hold promise for future exploration. While most of the existing research addresses children or teenagers and their families, less is known about the role of family support and interaction around T1DM patients in the emerging adulthood stages, and further exploration of transitions between developmental periods is yet to be exhausted. In better understanding not just "what works" but also "how it works", we will be able to propose a better future for T1DM patients and those who care for them.

\section{Disclosure}

The authors report no conflicts of interest in this work.

\section{References}

1. American Diabetes Association. Diagnosis and classification of diabetes mellitus. Diabetes Care. 2010;33(Suppl 1):S62-S69.
2. Centers for Disease Control and Prevention. National Diabetes Statistics Report: Estimates of Diabetes and its Burden in the United States. Atlanta, GA: US Department of Health and Human Services; 2014.

3. Dabelea D, Mayer-Davis EJ, Saydah S, et al; SEARCH for Diabetes in Youth Study. Prevalence of type 1 and type 2 diabetes among children and adolescents from 2001 to 2009. JAMA. 2014;311(17): $1778-1786$.

4. Atkinson MA, Eisenbarth GS, Michels AW. Type 1 diabetes. Lancet. 2014;383(9911):69-82.

5. Bach JF, Chatenoud L. The hygiene hypothesis: an explanation for the increased frequency of insulin-dependent diabetes. Cold Spring Harb Perspect Med. 2012;2(2):a007799.

6. Patterson C, Guariguata L, Dahlquist G, Soltész G, Ogle G, Silink M. Diabetes in the young-a global view and worldwide estimates of numbers of children with type 1 diabetes. Diabetes Res Clin Pract. 2014;103(2):161-175.

7. Soltesz G, Patterson C, Dahlquist G. Worldwide childhood type 1 diabetes incidence-what can we learn from epidemiology? Pediatr Diabetes. 2007;8(s6):6-14.

8. Cummins E, Royle P, Snaith A, et al. Clinical effectiveness and costeffectiveness of continuous subcutaneous insulin infusion for diabetes: systematic review and economic evaluation. Health Technol Assess. 2010;14(11):iii-iv, xi-xvi, 1-181.

9. Pihoker C, Badaru A, Anderson A, et al; SEARCH for Diabetes in Youth Study Group. Insulin regimens and clinical outcomes in a type 1 diabetes cohort: the SEARCH for diabetes in youth study. Diabetes Care. 2013;36(1):27-33.

10. Rausch JR, Hood KK, Delamater A, et al. Changes in treatment adherence and glycemic control during the transition to adolescence in type 1 diabetes. Diabetes Care. 2012;35(6):1219-1224.

11. Yeh H, Lau BD, Golden SH, Donner T, Brown TT, Bass EB. Insulin Delivery and Glucose Monitoring Methods: Future Research Needs. Agency for Healthcare Research and Quality; US Department of Health and Human Services, Rockville, MD. 2013.

12. Peters A, Laffel L, American Diabetes Association Transitions Working Group. Diabetes care for emerging adults: recommendations for transition from pediatric to adult diabetes care systems: a position statement of the american diabetes association, with representation by the american college of osteopathic family physicians, the american academy of pediatrics, the american association of clinical endocrinologists, the american osteopathic association, the centers for disease control and prevention, children with diabetes, the endocrine society, the international society for pediatric and adolescent diabetes, juvenile diabetes research foundation international, the national diabetes education program, and the pediatric endocrine society (formerly lawson wilkins pediatric endocrine society). Diabetes Care. 2011;34(11):2477-2485.

13. Johnson B, Elliott J, Scott A, Heller S, Eiser C. Medical and psychological outcomes for young adults with type 1 diabetes: no improvement despite recent advances in diabetes care. Diabetic Med. 2014;31(2): 227-231.

14. Rosenbauer J, Dost A, Karges B, et al; DPV Initiative and the German BMBF Competence Network Diabetes Mellitus. Improved metabolic control in children and adolescents with type 1 diabetes: a trend analysis using prospective multicenter data from germany and austria. Diabetes Care. 2012;35(1):80-86.

15. Simsek DG, Aycan Z, Özen S, et al. Diabetes care, glycemic control, complications, and concomitant autoimmune diseases in children with type 1 diabetes in turkey: a multicenter study. J Clin Res Pediatr Endocrinol. 2013;5(1):20-26.

16. Rewers M, Pihoker C, Donaghue K, Hanas R, Swift P, Klingensmith GJ. Assessment and monitoring of glycemic control in children and adolescents with diabetes. Pediatr Diabetes. 2009;10(s12):71-81.

17. American Diabetes Association. Executive summary: standards of medical care in diabetes - 2011. Diabetes Care. 2011;34(Suppl 1): S4-S10. 
18. American Diabetes Association. Standards of medical care in diabetes 2014. Diabetes Care. 2014;37(Suppl 1):S14-S80.

19. Miller KM, Beck RW, Bergenstal RM, et al. T1D Exchange Clinic Network. Evidence of a strong association between frequency of self-monitoring of blood glucose and hemoglobin A1c levels in T1D exchange clinic registry participants. Diabetes Care. 2013;36(7): 2009-2014.

20. Ziegler R, Heidtmann B, Hilgard D, Hofer S, Rosenbauer J, Holl R. Frequency of SMBG correlates with HbAlc and acute complications in children and adolescents with type 1 diabetes. Pediatr Diabetes. 2011;12(1):11-17.

21. Shorer M, David R, Schoenberg-Taz M, Levavi-Lavi I, Phillip M, Meyerovitch J. Role of parenting style in achieving metabolic control in adolescents with type 1 diabetes. Diabetes Care. 2011;34(8): 1735-1737.

22. Hanna KM. A framework for the youth with type 1 diabetes during the emerging adulthood transition. Nurs Outlook. 2012;60(6):401-410.

23. Seaquist ER, Anderson J, Childs B, et al. Hypoglycemia and diabetes: a report of a workgroup of the american diabetes association and the endocrine society. Diabetes Care. 2013;36(5):1384-1395.

24. Johnson S, Cooper M, Davis E, Jones T. Hypoglycaemia, fear of hypoglycaemia and quality of life in children with type 1 diabetes and their parents. Diabetic Med. 2013;30(9):1126-1131.

25. Kichler JC, Moss A, Kaugars AS. Behavioral factors influencing health outcomes in youth with type 1 diabetes. US Endocrinol. 2012;8(2): $77-83$.

26. Luyckx K, Vanhalst J, Seiffge-Krenke I, Weets I. A typology of coping with type 1 diabetes in emerging adulthood: associations with demographic, psychological, and clinical parameters. J Behav Med. 2010; 33(3):228-238.

27. Marshall M, Carter B, Rose K, Brotherton A. Living with type 1 diabetes: perceptions of children and their parents. J Clin Nurs. 2009;18(12): 1703-1710.

28. Ginsburg KR, Howe CJ, Jawad AF, et al. Parents' perceptions of factors that affect successful diabetes management for their children. Pediatrics. 2005;116(5):1095-1104.

29. Lewandowski A, Drotar D. The relationship between parent-reported social support and adherence to medical treatment in families of adolescents with type 1 diabetes. J Pediatr Psychol. 2007;32(4): 427-436.

30. Bowes S, Lowes L, Warner J, Gregory JW. Chronic sorrow in parents of children with type 1 diabetes. J Adv Nurs. 2009;65(5):992-1000.

31. Danne T, Battelino T, Jarosz-Chobot P, et al; PedPump Study Group. Establishing glycaemic control with continuous subcutaneous insulin infusion in children and adolescents with type 1 diabetes: experience of the PedPump study in 17 countries. Diabetologia. 2008;51(9): 1594-1601

32. Zysberg L, Lang T, Zisberg A. Parents' emotional intelligence and children's type I diabetes management. J Health Psychol. 2013;18(9): 1121-1128.

33. Smith LB, Kugler BB, Lewin AB, Duke DC, Storch EA, Geffken GR. Executive functioning, parenting stress, and family factors as predictors of diabetes management in pediatric patients with type 1 diabetes using intensive regimens. Child Health Care. 2014;43(3):234-252.

34. Pendley JS, Kasmen LJ, Miller DL, Donze J, Swenson C, Reeves G. Peer and family support in children and adolescents with type 1 diabetes. J Pediatr Psychol. 2002;27(5):429-438.

35. Coyne JC, Anderson BJ. The "psychosomatic family" reconsidered: diabetes in context. J Marital Fam Ther. 1988;14(2):113-123.

36. Danne T, Battelino T, Jarosz-Chobot P, et al. Establishing glycaemic control with continuous subcutaneous insulin infusion in children and adolescents with type 1 diabetes: experience of the PedPump study in 17 countries. Diabetologia. 2008;51(9):1594-1601.

37. Cameron FJ, Skinner TC, de Beaufort CE, et al. Hvidoere Study Group on Childhood Diabetes. Are family factors universally related to metabolic outcomes in adolescents with type 1 diabetes? Diabetic Med. 2008;25(4):463-468.
38. Lewin AB, Heidgerken AD, Geffken GR, et al. The relation between family factors and metabolic control: the role of diabetes adherence. J Pediatr Psychol. 2006;31(2):174-183.

39. Silverstein J, Klingensmith G, Copeland K, et al; American Diabetes Association. Care of children and adolescents with type 1 diabetes: a statement of the american diabetes association. Diabetes Care. 2005;28(1):186-212.

40. Whittemore R, Jaser S, Chao A, Jang M, Grey M. Psychological experience of parents of children with type 1 diabetes: a systematic mixed-studies review. Diabetes Educ. 2012;38(4):562-579.

41. Murphy H, Rayman G, Skinner T. Psycho-educational interventions for children and young people with type 1 diabetes. Diabetic Med. 2006;23(9):935-943.

42. Law EF, Fisher E, Fales J, Noel M, Eccleston C. Systematic review and meta-analysis of parent and family-based interventions for children and adolescents with chronic medical conditions. J Pediatr Psychol. 2014;39(8):866-886.

43. DiMatteo MR. Social support and patient adherence to medical treatment: a meta-analysis. Health Psychol. 2004;23(2):207.

44. Hampson SE, Skinner TC, Hart J, et al. Effects of educational and psychosocial interventions for adolescents with diabetes mellitus: a systematic review. Health Technol Assess. 2001;5(10):1-79.

45. Northam E, Todd S, Cameron F. Interventions to promote optimal health outcomes in children with type 1 diabetes - are they effective? Diabetic Med. 2006;23(2):113-121.

46. McGrady ME, Laffel L, Drotar D, Repaske D, Hood KK. Depressive symptoms and glycemic control in adolescents with type 1 diabetes: mediational role of blood glucose monitoring. Diabetes Care. 2009; 32(5):804-806.

47. Biessels GJ, Deary IJ, Ryan CM. Cognition and diabetes: a lifespan perspective. Lancet Neurol. 2008;7(2):184-190.

48. Schoenle E, Schoenle D, Molinari L, Largo R. Impaired intellectual development in children with type I diabetes: association with $\mathrm{HbA} 1 \mathrm{c}$, age at diagnosis and sex. Diabetologia. 2002;45(1):108-114.

49. Fox SE, Levitt P, Nelson IIICA. How the timing and quality of early experiences influence the development of brain architecture. Child Dev. 2010;81(1):28-40.

50. Kakleas K, Kandyla B, Karayianni C, Karavanaki K. Psychosocial problems in adolescents with type 1 diabetes mellitus. Diabetes Metab. 2009;35(5):339-350.

51. Neumark-Sztainer D, Patterson J, Mellin A, et al. Weight control practices and disordered eating behaviors among adolescent females and males with type 1 diabetes: associations with sociodemographics, weight concerns, familial factors, and metabolic outcomes. Diabetes Care. 2002;25(8):1289-1296.

52. Mannucci E, Rotella F, Ricca V, Moretti S, Placidi G, Rotella C. Eating disorders in patients with type 1 diabetes: a meta-analysis. J Endocrinol Invest. 2005;28(7):417-419.

53. Goebel-Fabbri AE. Disturbed eating behaviors and eating disorders in type 1 diabetes: clinical significance and treatment recommendations. Curr Diab Rep. 2009;9(2):133-139.

54. Lee P, Greenfield J, Campbell L. Managing young people with type 1 diabetes in a 'rave' new world: metabolic complications of substance abuse in type 1 diabetes. Diabetic Med. 2009;26(4):328-333.

55. McLellan AT, Lewis DC, O’Brien CP, Kleber HD. Drug dependence, a chronic medical illness: implications for treatment, insurance, and outcomes evaluation. JAMA. 2000;284(13):1689-1695.

56. Cameron FJ, Northam EA, Ambler GR, Daneman D. Routine psychological screening in youth with type 1 diabetes and their parents: a notion whose time has come? Diabetes Care. 2007;30(10):2716-2724.

57. Smetana JG. Parenting styles and conceptions of parental authority during adolescence. Child Dev. 1995;66(2):299-316.

58. Baumrind D. Child care practices anteceding three patterns of preschool behavior. Genet Psychol Monogr. 1967;75(1):43-88.

59. Wysocki T, Harris MA, Greco P, et al. Randomized, controlled trial of behavior therapy for families of adolescents with insulin-dependent diabetes mellitus. J Pediatr Psychol. 2000;25(1):23-33. 
60. Merkel RM, Wright T. Parental self-efficacy and online support among parents of children diagnosed with type 1 diabetes mellitus. Pediatr Nurs. 2012;38(6):303-308.

61. Lindström C, Åman J, Norberg A. Increased prevalence of burnout symptoms in parents of chronically ill children. Acta Paediatr. 2010;99(3):427-432.

62. Deschamps I, Lestradet H, Busson M, Hors J. Evaluation of recurrence risk in siblings of diabetic children: importance of age and birth order in relation to HLA genotypes. Diabetes Res. 1984;1(3):125-130.

63. Drotar D, Crawford P. Psychological adaptation of siblings of chronically iII children: research and practice implications. J Dev Behav Pediatr. 1985;6(6):355-362.

64. Anderson BJ, Brackett J, Ho J, Laffel LM. An office-based intervention to maintain parent-adolescent teamwork in diabetes management impact on parent involvement, family conflict, and subsequent glycemic control. Diabetes Care. 1999;22(5):713-721.

65. Laffel LM, Vangsness L, Connell A, Goebel-Fabbri A, Butler D, Anderson BJ. Impact of ambulatory, family-focused teamwork intervention on glycemic control in youth with type 1 diabetes. J Pediatr. 2003;142(4):409-416.

66. Martins A, Ramalho N, Morin E. A comprehensive meta-analysis of the relationship between emotional intelligence and health. Pers Individ Dif. 2010;49(6):554-564.

67. Zysberg L, Bar Yosel T, Goldman M. Emotional intelligence and glycemic management among type I diabetes patients. J Health Psychol. In press 2015.

68. Bobrow ES, AvRuskin TW, Siller J. Mother-daughter interaction and adherence to diabetes regimens. Diabetes Care. 1985;8(2):146-151.

69. Satin W, La Greca AM, Zigo MA, Skyler JS. Diabetes in adolescence: effects of multifamily group intervention and parent simulation of diabetes. J Pediatr Psychol. 1989;14(2):259-275.
70. Delamater AM, Smith JA, Bubb J, et al. Family-Based Behavior Therapy for Diabetic Adolescents. University of Florida Press: Gainesville, FL, USA. 1991.

71. Greco P, Pendley JS, McDonell K, Reeves G. A peer group intervention for adolescents with type 1 diabetes and their best friends. $J$ Pediatr Psychol. 2001;26(8):485-490.

72. Ellis DA, Frey MA, Naar-King S, Templin T, Cunningham P, Cakan N. Use of multisystemic therapy to improve regimen adherence among adolescents with type 1 diabetes in chronic poor metabolic control: a randomized controlled trial. Diabetes Care. 2005;28(7):1604-1610.

73. Teufel-Shone NI, Drummond R, Rawiel U. COMMUNITY CASE STUDY developing and adapting a family-based diabetes program at the US-mexico border. Prev Chronic Dis. 2005;2(1):A20.

74. Carr A. The effectiveness of family therapy and systemic interventions for child-focused problems. J Fam Ther. 2009;31(1):3-45.

75. Sullivan-Bolyai S, Bova C, Leung K, Trudeau A, Lee M, Gruppuso P. Social support to empower parents (STEP): an intervention for parents of young children newly diagnosed with type 1 diabetes. Diabetes Educ. 2010;36(1):88-97.

76. Stanger C, Ryan SR, Delhey LM, et al. A multicomponent motivational intervention to improve adherence among adolescents with poorly controlled type 1 diabetes: a pilot study. J Pediatr Psychol. 2013;38(6): 629-637.

77. Herbert LJ, Mehta P, Monaghan M, Cogen F, Streisand R. Feasibility of the SMART project: a text message program for adolescents with type 1 diabetes. Diabetes Spectr. 2014;27(4):265-269.

78. Grey M, Jaser SS, Whittemore R, Jeon S, Lindemann E. Coping skills training for parents of children with type 1 diabetes: 12-month outcomes. Nurs Res. 2011;60(3):173-181.
Patient Intelligence

\section{Publish your work in this journal}

Patient Intelligence is an international, peer-reviewed, open access journal that characterizes and measures the central role of patient behavior and intention in optimizing healthcare management in all areas of disease and complaint types. An improved understanding of patient intelligence coupled with predictive analysis helps an organization contribute more effectively to achieving better outcomes.

Submit your manuscript here: http://www.dovepress.com/patient-intelligence-journal

\section{Dovepress}

The journal is characterized by the rapid reporting of reviews, original research, methodologies, analytics, modeling, clinical studies and patient surveys across all disease areas. The manuscript management system is completely online and includes a very quick and fair peer-review system. Visit http://www.dovepress.com/ testimonials.php to read real quotes from published authors. 